\title{
Relationship Awareness: How Managers Can Improve Employee Performance
} By Dan Oedekoven and John Hay

I $\mathrm{n}$ today's complex and ever-changing work environment, we are surrounded by and interact with many different personality types on a daily basis. The success or failure of our individual objectives relies heavily upon the results of these interactions. For example, we have all noticed that some people like to be in charge. They really enjoy making decisions. They are usually very competitive and would prefer to take immediate action. Some others tend to take a long time to make a decision; they prefer to make the "right" decision rather than several. These different personality traits show how people act and react differently in certain situations. Due to these behavioral differences, we need to interact accordingly with how they will best respond.

Misunderstandings, hurt feelings, or other disruptions between co-workers can not only disrupt the work place, but also decrease productivity, thus increasing costs. As managers it is important to help people find the right "place" in our organizations, places where they will be most productive and enjoy a high level of job satisfaction. With increased job satisfaction and productivity companies can maintain low employee turnover, which not only will help them achieve greater levels of economies of experience, but also reduces the cost of training and human resource issues that arise in a conflicted setting.

\section{History of Behavioral Analysis}

Throughout history many people have added to the field of behavior analysis. Sir Francis Galton, who is generally regarded as the father of psychometrics (which includes the measurement of knowledge, abilities, attitudes, and personality traits), has greatly added to this field. Through his research he began what has today become the field of behavior genetics. Galton performed many behavior experiments and coined the phrase "nature versus nurture." These experiments relied heavily on the use of twins and led him to conclude that the evidence favored nature over nurture. In pioneering the field of psychometrics Galton opened the door for others to follow in his footsteps. ${ }^{1}$ Carl Gustav Jung early in the 20th century categorized human behavior under four separate groups: "Rational" (judging) functions: thinking and feeling, and the "irrational (perceiving) functions: sensing and intuition. These functions were moderated by the idea of introversion and extraversion. ${ }^{2}$ With the addition of Jung's work and the beginning of a behavior map based on the four behavioral types, tools began to be developed so we would be able to categorize and sort ourselves into groups based on our behavior. This has allowed people to realize how they could more effectively interact with each other, mutually benefiting all parties.

\section{Tools to Indicate Behavior Types}

A number of psychometric personality instruments have been created through the years to help identify various personality types. Some of the better known instruments are the Dominance, Influence, Steadiness, Conscientious (DISC) instrument developed by Walter V. Clarke and Associates based on the work of William Moulton Marston, and the Myers-Briggs Type Indicator developed by Katharine Cook Briggs and her daughter, Isabel Briggs Myers, based on work done by Jung. The Myers-Briggs indicator has 16 different personality types based on four pairs of preferences or dichotomies: Extrovert vs. Introvert; Sensing vs. iNtuition; Thinking vs. Feeling; Judging vs. Perceiving (ESTJ vs. INFP). ${ }^{2}$

Another instrument is based on the Relationship Awareness ${ }^{\circledR}$ theory developed in 1970 by Elias H. Porter, who studied under Carl Rogers at the University of Chicago. Porter said, "The more we know about ourselves and others, the more able we are to build productive relationships." His Motivational Value System (MVS) is measured by the Strength Deployment Inventory (SDI). It has four basic categories and combinations of those over a spectrum that resembles a triangle. Each corner represents a particular MVS. The fourth MVS is the center of the triangle (Fig. 1). Porter also noted that our motives and behavior (or MVS) may change when we are faced with opposition or conflict. Porter's research also found that strengths when taken to excess become weaknesses. ${ }^{3}$ 


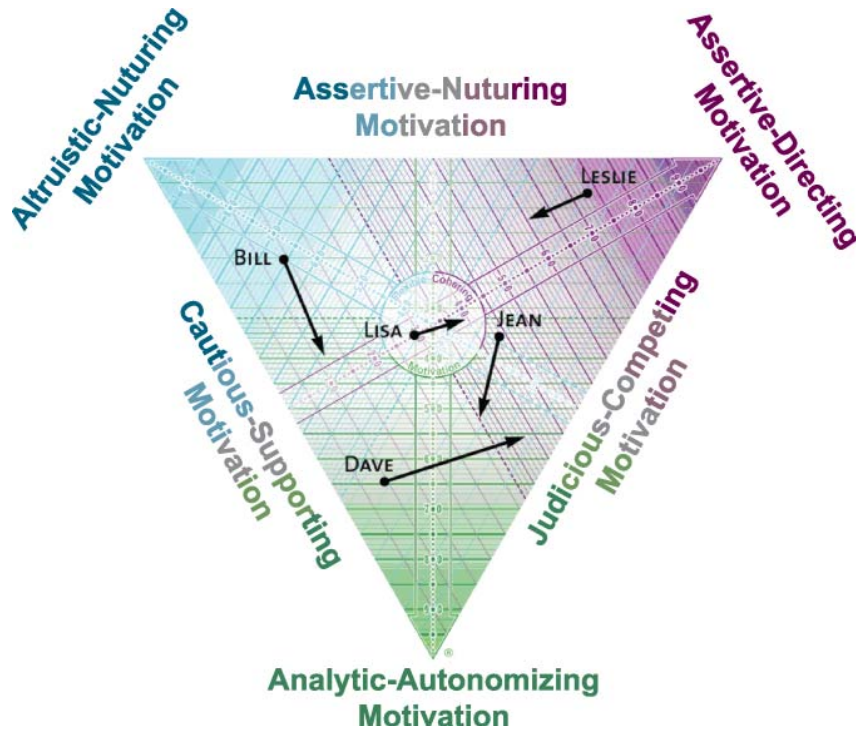

Figure 1. Strength Deployment Inventory triangle, made up from the four motivational value systems.

\section{Implementing the Tools}

An excellent personality profile instrument was developed by the United States Department of Veterans Affairs entitled Interpersonal Styles. ${ }^{4}$ It develops the personality discussion around four types: Red, Green, Blue, and the Hub (sometimes called the Silver).

\section{"Red"}

Let's examine these ideas in more detail. The individual that we discussed earlier who likes to make decisions is a "Red" or highly directive personality. They would identify with these descriptors: direct, demanding, risk-taker, adventuresome, decisive, competitive, enterprising, self-confident, quick to act, and forceful. Their major focus is controlling the environment. "Do it and do it now" or "I'm in charge." Their basic needs are authority, challenges, prestige, varied activities, difficult assignments, logical approaches, and opportunities to advance. Their fears and concerns would include being taken advantage of, losing control of the situation, boredom, being tied to a routine, or appearing weak or soft. They are seen positively as independent, decisive, efficient, and competitive. If these strengths become overdone, they are seen negatively as dominating, abrasive, pushy, touchy, and arrogant.

To be more effective, a highly directive personality needs to do the following:

- Develop more patience with other people

- Learn to negotiate with others

- Develop greater awareness of other people's needs

- Participate more with others

To be more effective in working with a highly directive personality, others need to do the following:

- Be clear, specific, brief, to the point

- Stick to business
- Come prepared with requirements, objectives, and support material

- Present material in a logical format

- Provide alternatives/choices for making "their" decision

- Take issue with facts and not people when disagreeing

- Support rather than direct or order

- Depart graciously

"Green"

The next type we will examine is the "Green" or highly analytic personality. Words that might describe this kind of person are cautious, practical, analytical, orderly, persevering, and methodical. Their major focus is discovering what is the "right" or correct way. Their basic needs are security, no sudden changes, personal attention, exact job descriptions, and a controlled work environment. Their fears and concerns are unwarranted personal criticism, criticism of what they have done, and spontaneous displays of feelings or emotions. They are seen positively as industrious, objective, orderly, precise, and prudent. When these strengths become overdone, they can be seen negatively as indecisive, rigid, picky, stuffy, or critical.

To be more effective, a highly analytic personality needs to do the following:

- Develop more comfort with emotionally charged situations

- Learn to value informal interactions with others

- Adjust standards to the needs of the environment

To be more effective in working with a highly analytic personality, others need to do the following:

- Approach in a straightforward manner (stick to business)

- Build credibility by offering pros and cons to suggestions

- Do what you say you will do

- Present an implementation plan with timetables

- Ensure no surprises

- Provide follow-through when agreeing

- Make an organized presentation when disagreeing

- Give time to verify reliability of actions

"Blue"

A third is the "Blue" type or highly expressive personality. Unlike the "Red" and "Green," this individual is more concerned about "people and process" than about "facts and product or outcomes." A description of a blue personality would be persuasive, impulsive, self-promoting, trusting, helpful, emotional, idealistic, detail-avoider, achiever, and caring. Their major focus is on others. Their basic need is social recognition. They want to be popular and need people to talk to. They like freedom from control and detail and work best in favorable work conditions. They need recognition of their abilities and genuinely want to help others. Their fears and concerns are being blamed for things going 
wrong, having people be upset with them, not being liked, and public humiliation. They are seen positively as dramatic, enthusiastic, creative, and outgoing. When these are overdone they are seen negatively as excitable and impractical. Some have described their crisis situation as "When in worry, when in doubt: run in circles, scream and shout!"

To be more effective, a highly expressive personality needs to do the following:

- Be more objective in making decisions

- Develop more organized, systematic approaches to tasks

- Improve follow-through by attending to key details

- Learn to be more direct

- Have better control over use of time

To be more effective in working with a highly expressive personality, others need to do the following:

- Plan interactions that support interaction

- Allow time for relating/socializing

- Talk about people and their goals

- Recognize that tasks/assignments are followed up best when in writing

- Ask for opinions/ideas

- Provide approaches to implementing actions

- Provide testimonials from people seen as important or prominent

- Offer special, immediate, and extra incentives for willingness to participate

\section{"Silver"}

The final type is "Silver" or "Hub" style, a highly adaptive personality. Some concepts that would describe them are loyal, predictable, team person, serene, possessive, supportive, accepting, compromising, indecisive, and humble. Like the "Blue" they are more concerned about people than about outcomes. Their major focus is about cooperating with others. Their basic needs are status quo, security, time to adjust, appreciation, identification with the group, work patterns, limited territory, and areas of specialization. Their fears and concerns are situations in which nobody knows what is happening, confusion and instability, and lack of clarity on expectations. They are seen positively as supportive, dependable, agreeable, empathetic, and loyal. When overdone their actions cause them to be seen negatively as dependent, subjective, pliable, manipulative, and sentimental.

To be more effective, a highly adaptive personality needs to do the following:

- Learn to handle change better

- Become more assertive

- Increase comfort with open conflict

- Vary routines occasionally

- Speak up when concerned or bothered

To be more effective in working with a highly adaptive personality, others need to do the following:
- Start, however briefly, with a personal comment

- Draw out personal goals patiently

- Listen and be responsive

- Present information in a nonthreatening manner

- Watch for areas of possible disagreement (employ flight rather than fight)

- Watch for hurt feelings when disagreeing

- Define individual contributions clearly (preferably in writing)

- Provide guarantees that decisions will minimize risks

\section{Helpful Hints}

Sometimes we can get a "feel" for how a person might behave by how they dress, talk, or act. A "Red" will dress simply and functionally. They talk fast with intensity, sometimes in a monotone, and they tend to interrupt. They talk about goals and facts. They tend to point and lean forward while talking. They usually have direct eye contact with rigid or controlled facial expressions. They tend to make lists and cross items off as they are accomplished. Occasionally they have been known to write things on their list that they have already accomplished just so they can cross them off. They usually have more things on their "To Do" list than they have time to reasonably accomplish. They are usually late for meetings because they have so many items on their list. Their environment usually has action mementos, sometimes referred to as hard-charging clutter.

A "Green" will dress conservatively and somewhat understated. They will talk slowly, softly, infrequently, and often in a monotone. They talk about tasks and facts or data. They will usually lean back with their hands together and have indirect eye contact with rigid controlled facial expressions. These folks have actually read the handbook, operator's manual, or assembly instruction manual and can tell you in what general area of that manual information about specific subjects can be found. (They may have written the manual in the first place.) Their environment is very neat and orderly and sometimes filled with charts, graphs, or spreadsheets, depending on their job description.

The "Blue" will dress very colorfully. They usually stand out from the crowd. "Blue" females tend to wear a little more make-up and jewelry than other types. They will be color coordinated. They tend to talk fast, loudly, and frequently with inflection. They tend to lean forward and gesture with direct eye contact. They are usually very open or casual with animated facial expressions. They talk about people and relationships. "Blues" are sometimes described as "The Life of the Party." They tend to be very creative or artistic individuals. Their environment is full of personal effects such as photos of family and friends, sometimes described as a "homey" look. Their space will be well decorated and often has a theme that may change with the season or holiday.

The "Hub" (Silver) like the "Blue" tends to dress with a little more color, often with a company logo or other "team" 
affiliation. They tend to talk slowly and softly with inflection but usually to respond, not to interrupt or to stimulate conversation. They are "big picture" individuals who talk about groups and opinions. They tend to be a combination of all the other groups (thus the name Hub) so they "see" things from all the others' perspective. This can lead to difficult, some would say "wishy-washy," decision making. They may lean back with their hands together. They will probably have indirect eye contact with animated facial expressions. Their environment will probably include some inspirational posters and perhaps something about their favorite tractor brand, breed of livestock, or sports team.

\section{Introvert or Extrovert, How Personality Types Can Behave Differently}

One final thought about individual's motivation and behavior. We are all either an introvert or an extrovert. By analyzing our behavior we can see which of these categories we fall into. When thinking about the most stressful day we could have, focus on that day in your mind. What does it look like? How does it feel? What is creating that stress? Now, what do you do when that day is over and you can "recharge" your batteries? Do you need a little time by yourself? Or do you need a few friends to gather around? If you are in the first category, you are probably an introvert. If you are in the second, then you are probably an extrovert. This will change your behavior and the behavior of the people in your organization or business. A "Blue" who needs people will behave differently if they are an introvert than if they are an extrovert. The same is true for each of the other "colors" as well.

\section{Concluding Thoughts}

Interacting with others, especially in a work setting, is a complex system with many components. We need to realize that our actions may positively or negatively affect the entire system, not just the individual with whom we are dealing. We must also realize that while one person could respond positively to a situation, another may view it negatively. It is crucial to understand that past experiences, personality, and perception can affect how an individual will react to a decision or situation, as well as how they interact with others. As managers, we must always look at how our decisions affect the motivation and behavior of others. By using these tools we will start to see changes in both our personal and professional lives. This in turn will lead to a more productive and efficient work environment, and to richer and fuller lives.

Porter said, "The more a personality theory can be for a person, rather than about a person, the better it will serve that person." This can be overlapped into the idea that the more a personality type can be fitted to a job that complements their personal style, then the more productive and efficient the work place will become. For instance, you would not want to put a "Blue" extrovert in a line camp by themselves with no one to talk to for months at a time. So the focus of any discussion on personality types should be about helping people find a relationship that "fits" their specific personality.

\section{References}

1. SAndall, R. 2008. Sir Francis Galton and the roots of eugenics. Society 45:170-176.

2. Carlyn, M. 1977. An assessment of the Myers-Briggs Type Indicator. Journal of Personality Assessment 41(5):461-473.

3. Scudder, T. 2007. Strength Deployment Inventory: facilitator guide. 3rd ed. Carlsbad, CA, USA: Personal Strengths Publishing.

4. US Veterans Affairs Staff. 1992. Team leader appendix. In: Department of Veterans Affairs total quality improvement team leader/facilitator skills instructor guide. Washington, DC, USA: US Government Printing Office. p. 23-27.

Authors are Extension Specialist, Community Innovation $\varepsilon^{\circ}$ Leadership, South Dakota State University Cooperative Extension Service, West River Ag Center, Rapid City, SD 57702, USA (Oedekoven); and Graduate Assistant and Tio Kleberg Fellow, King Ranch Institute for Ranch Management, Texas Aङ'M University-Kingsville, Kingsville, TX 78363, USA (Hay). 